\title{
Effect of co-twin gender on neurodevelopmental symptoms: a twin register study
}

\author{
Jonna Maria Eriksson ${ }^{{ }^{*}}$ (D), Sebastian Lundström ${ }^{2,3}$, Paul Lichtenstein ${ }^{4}$, Susanne Bejerot ${ }^{1,5}$ and Elias Eriksson ${ }^{6}$
}

\begin{abstract}
Background: Autism spectrum disorder (ASD) and attention-deficit/hyperactivity disorder (ADHD) are neurodevelopmental disorders thought to have both genetic and environmental causes. It has been hypothesized that exposure to elevated levels of prenatal testosterone is associated with elevated traits of ASD and ADHD. Assuming that testosterone levels from a dizygotic male twin fetus may lead to enhanced testosterone exposure of its co-twins, we aimed to test the prenatal testosterone hypothesis by comparing same-sex with opposite-sex dizygotic twins with respect to neurodevelopmental symptoms.

Methods: Neuropsychiatric traits were assessed in a population-based twin cohort from the Child and Adolescent Twin Study in Sweden (CATSS). Parental interviews were conducted for 16,312 dizygotic twins, 9 and 12 years old, with the Autism - Tics, ADHD, and other Comorbidities inventory (A-TAC).

Results: Girls with a female co-twin had an increased risk of reaching the cut-off score for ADHD compared with girls with a male co-twin. Both boys and girls with a female co-twin displayed a larger number of traits related to attention deficit and repetitive and stereotyped behaviors than those with a male twin. In girls, this also extended to social interaction and the combined measures for ASD and ADHD, however, with small effect sizes.

Conclusions: Our results are reverse to what would have been expected from the prenatal testosterone hypothesis but consistent with a previous study of ASD and ADHD traits in dizygotic twins. The seemingly protective effect for girls of having a twin brother may be an effect of parent report bias, but may also be an unexpected effect of sharing the intrauterine environment with a male co-twin.
\end{abstract}

Keywords: Twin study, Autistic disorder, Asperger syndrome, Attention-deficit hyperactivity disorders, Symptom assessment

\section{Background}

Autism spectrum disorder (ASD) and attention-deficit/ hyperactivity disorder (ADHD) are neurodevelopmental disorders that are more commonly diagnosed in males than in females. The heritability is high in both ASD [1] and ADHD [2], but no individual gene variants exerting a major impact on the susceptibility have as yet been identified $[1,2]$. Further, ASD and ADHD are frequently cooccurring, implying some shared etiology [3]. There is some evidence that dizygotic twins are more concordant

\footnotetext{
* Correspondence: jonna.eriksson@gmail.com

${ }^{1}$ Department of Clinical Neuroscience, Karolinska Institutet, KIND, Gävleg 22,

SE-113 30, Stockholm, Sweden

Full list of author information is available at the end of the article
}

for ASD than non-twin siblings, indicating that also intrauterine factors may be involved [4].

Several possible explanations for the high male-tofemale ratio in autism have been put forward. The sexdifferential threshold liability model for ASD proposes that a greater genetic burden is required for females than for males to develop ASD, implicating the existence of a yet unidentified female protective effect [5-7]. The extreme male brain theory of autism, on the other hand, describes an autistic personality characterized by extremes of typical male personality traits [8] in terms of systemizing skills and weaknesses in empathy [9]. This connection to sex-related differences might be one clue to the etiologies of ASD, and it has been hypothesized 
that exposure to elevated levels of prenatal testosterone is associated with more autistic traits and thus also may be a risk factor for developing ASD. This has been supported by studies of the association between autistic traits and testosterone levels in amniotic fluid [10-12].

Testosterone passes the blood-brain barrier and binds to the androgen receptor in the brain in both males and females, and a permanent (organizational) impact of prenatal testosterone exposure on fetal neurodevelopment has been confirmed in animal studies [13]. The higher testosterone levels in male fetuses are reflected by considerably higher testosterone levels also in the amniotic fluid compared with those observed for female fetuses [14]. Studies on rodents have shown that testosterone from male fetuses transfer to adjacent fetuses via amniotic diffusion [15], and this phenomenon has been proposed to occur also in human twin pregnancies [16]. In this vein, studies of prenatal testosterone transfer in humans suggest that having a male co-twin may masculinize various aspects of the phenotype in women, including body mass index [17], tooth crown size [18], the eruption of teeth [19], the second- to fourth-digit ratio [20], leukocyte telomere length [21], and cerebral lateralization [22]. Some reports suggest that a corresponding virilization may take place also with respect to behavioral parameters, such as aggression [23] and sensation seeking [16, 24]; however, most of these studies have been based on small samples, and they are to some extent contradicted by reports failing to detect clear-cut behavioral differences between same-sex and oppositesex female twins [25-29]. Similarly controversial is the possible influence of having a male twin for the risk of developing disordered eating in females, some studies suggesting a protecting effect $[30,31]$ while others have failed to replicate this finding [32-34].

Assuming that having a male co-twin increases the prenatal exposure to testosterone, the prenatal androgenization theory of autism [10] would predict a higher rate of autistic traits in females with a male cotwin. Likewise, since also ADHD is more prevalent in males than females, and since it has been suggested that prenatal testosterone exposure of girls increases the risk also for ADHD [35], ADHD traits could also be expected to be enhanced in opposite-sex female twins. A previous study, comparing neuropsychiatric traits in dizygotic twins with either a male or a female co-twin, however, revealed the counter-intuitive result that female index twins with a male co-twin had a lower rate of parent-reported ADHDand ASD-related traits than those with a female co-twin [36]. In the present study, we have addressed the same issue by analyzing data obtained within the Child and Adolescent Twin Study in Sweden (CATSS) [37] on parent-reported symptoms of ADHD and ASD in dizygotic twins having either a male or female co-twin.

\section{Methods \\ Participants}

This study was conducted using data from CATSS, an ongoing, population-based longitudinal twin study targeting all twins born in Sweden since July 1, 1992, at 9 or 12 years of age. The CATSS has a response rate of $80 \%$ with little influence of the presence of neurodevelopmental disorders on the response rate [37]. Zygosity was determined by a DNA test [38]. A total of 8156 dizygotic twin pairs (4219 male-female, 1808 female-female, 2129 male-male) were included in the present study.

\section{The Autism-Tics, AD/HD, and other Comorbidities inventory}

ADHD and autistic traits were assessed with the Autism-Tics, AD/HD, and other Comorbidities inventory (A-TAC) [39-41] which is a parental telephone interview for assessing neuropsychiatric problems in children. All interviews were conducted by professional interviewers who had undergone a brief introduction to psychiatry and twin research. A-TAC comprises 96 questions organized in 20 modules regarding clinically meaningful areas of psychiatric or psychological problems. The ASD domain comprises three modules: "language," "social interaction," and "flexibility" (mirroring the DSM-IV subdomain of "restricted repetitive and stereotyped patterns"). The $\mathrm{AD} / \mathrm{HD}$ domain comprises the modules "impulsiveness/activity" and "concentration/attention." The remaining 15 modules cover symptoms on other neuropsychiatric problems with less specific relation to ASD or ADHD in the DSM-IV. Response options for each item are "yes" (1), "yes, to some extent" (0.5), and "no" (0). Seventeen items were used to assess behavior representing the different ASD criteria defined by the DSM-IV [37]. The A-TAC domain and module scores represent the summed scores of the included items. The internal consistency has been shown to be good for the 17 ASD items $(\alpha=0.86)$ and excellent for the $19 \mathrm{AD} / \mathrm{HD}$ items $(\alpha=0.90)$ [37]. The present study used the cut-offs for ASD and ADHD caseness from the A-TAC validation study [40]. Two cut-offs for ASD were used: a low cut-off of $\geq 4.5$ points, which yielded a sensitivity of 0.96 and specificity of 0.88 , and a high cut-off of $\geq 8.5$ points (sensitivity 0.71 , specificity 0.95 ). For $\mathrm{AD} / \mathrm{HD}$, a low cutoff of $\geq 6$ yielding a sensitivity of 0.98 and specificity of 0.81 , and a high cut-off of $\geq 12.5$ (sensitivity 0.52 , specificity 0.95 ) were used.

\section{Statistical analysis}

We studied differences in neuropsychiatric traits, as measured by the A-TAC modules, in index twins with either a female or male co-twin. In the main analysis, possible differences in scores for the composite modules for $\mathrm{ASD}$ and $\mathrm{AD} / \mathrm{HD}$ were analyzed. In sensitivity 
analyses, differences with respect to cut-off rates for these modules, as well as differences with respect to scores of individual ASD and AD/HD submodules, were assessed. The three remaining A-TAC single modules spanning at least 5 points or more in the cohort were also tested to serve as control variables. In same-sex pairs, the index twin was selected randomly, in oppositesex pairs the twin of the analyzed sex was selected as index twin. Due to non-normality and heterogeneity of variances of the residual distributions, we used MannWhitney $U$ test to analyze differences in module scores between index twins with a co-twin brother and index twins with a co-twin sister. The chi-square test was used to compare proportions of above cut-off scores between groups. In all analyses, both twins were excluded if either twin had a missing module score (46 pairs $(0.6 \%)$ for ASD score and 65 pairs $(0.8 \%)$ for ADHD score). Quade's rank analysis of covariance [42] was used to analyze interaction effects. Since the main analysis comprises only two comparisons, and the other comparisons are to be regarded as sensitivity analyses, no correction of $p$ values for multiple comparisons was deemed necessary.

\section{Ethics statement}

Participants in the CATSS study are protected by informed consent process-they are informed of what is being collected and given the option to withdraw their consent and discontinue participation. The CATSS-9/12 study has ethical approval from the Karolinska Institute Ethical Review Board: Dnr 02-289 and 2010/507-31/1.

\section{Results}

\section{Distribution of scores}

As could be expected, the score of the outcome variables were extremely skewed. A total of $48 \%$ of the male twins and $58 \%$ of the female twins scored 0 points on autistic traits (Table 1). The female index twins with a female co-twin scored higher than the female index twins with a male co-twin on both autistic traits and ADHD traits (Table 2) but with small effects $(r<0.1)$. There was no significant interaction effect between cotwin sex and age on autistic traits or autistic traits. Neither was there any interaction between co-twin sex and ADHD traits on autistic traits nor between co-twin sex and autistic traits on ADHD traits.

\section{Exploring the single modules}

To further explore the results above, the differences in rank scores were also tested in each of the A-TAC modules spanning at least 5 points in scores: all differences pointed to a higher rank sum in the index twins with a female co-twin. Among the girls, the index twins with a female co-twin had higher rank scores than those with a
Table 1 Distribution of scores (\%) for index twins with either a female or male co-twin

\begin{tabular}{|c|c|c|c|c|c|c|c|c|}
\hline & \multicolumn{4}{|c|}{ ADHD } & \multicolumn{4}{|l|}{ ASD } \\
\hline & $\overline{\mathrm{FF}}$ & $F M$ & MF & $\overline{\mathrm{MM}}$ & $\overline{\mathrm{FF}}$ & $F M$ & MF & $\mathrm{MM}$ \\
\hline$\overline{0}$ & 45.1 & 47.4 & 34.2 & 35.5 & 55.7 & 60.6 & 47.7 & 48.2 \\
\hline 0.5 & 11.3 & 11.6 & 10.0 & 10.0 & 17.8 & 16.7 & 17.2 & 17.5 \\
\hline 1 & 8.2 & 8.9 & 7.6 & 8.2 & 11.1 & 9.3 & 12.7 & 11.5 \\
\hline 1.5 & 6.3 & 6.1 & 5.9 & 6.1 & 4.8 & 4.6 & 6.0 & 6.2 \\
\hline 2 & 4.8 & 5.4 & 5.7 & 4.7 & 3.4 & 2.8 & 4.8 & 4.8 \\
\hline 2.5 & 3.2 & 3.7 & 4.9 & 4.8 & 1.5 & 1.5 & 2.3 & 2.8 \\
\hline 3 & 3.4 & 3.1 & 4.0 & 3.9 & 1.6 & 1.2 & 2.0 & 1.7 \\
\hline 3.5 & 3.1 & 2.2 & 3.5 & 3.1 & 0.9 & 0.6 & 1.1 & 1.6 \\
\hline 4 & 2.3 & 2.0 & 2.7 & 2.9 & 0.6 & 0.6 & 0.9 & 0.9 \\
\hline $4.5-5$ & 2.9 & 2.7 & 5.4 & 5.5 & 0.9 & 0.5 & 1.7 & 1.2 \\
\hline $5.5-6$ & 2.5 & 2.3 & 3.7 & 3.6 & 0.4 & 0.4 & 0.9 & 0.8 \\
\hline $6.5-7$ & 1.7 & 1.2 & 2.9 & 2.7 & 0.3 & 0.3 & 0.7 & 0.8 \\
\hline $7.5-8$ & 1.0 & 0.7 & 1.9 & 1.5 & 0.2 & 0.1 & 0.6 & 0.4 \\
\hline$>8$ & 4.0 & 2.7 & 7.5 & 6.9 & 0.5 & 0.6 & 1.4 & 1.4 \\
\hline
\end{tabular}

ADHD and ASD scores from the Autism-Tics, AD/HD, and other Comorbidities inventory (A-TAC)

$F F$ female with a female co-twin, $F M$ female with a male co-twin, $M F$ male with female co-twin, $M M$ male with a male co-twin

male co-twin in four modules: "perception" $(U=$ $3,664,254, \quad p=0.004, \quad r=0.04)$, concentration/attention $(U=3,605,112, p=0.001, r=0.04)$, social interaction $(U=$ $3,659,944, p=0.01, r=0.03)$, and flexibility $(U=3,677,626$, $p=0.005, r=0.04)$. In boys, twins with a female co-twin had higher rank scores on concentration /attention $(U=$ $4,261,827, \quad p=0.003, \quad r=0.04)$ and flexibility $(U=$ $4,368,327, p=0.006, r=0.03)$ than those with a male cotwin. No differences were found in the modules language, impulsiveness/activity, "emotion," or "opposition."

\section{Differences in cut-off scores for ADHD and ASD}

The pattern of proportions of twins with either a male or female co-twin reaching the cut-off scores for ADHD and ASD were studied (Table 3). A higher frequency of index twins with a female co-twin that reached the low cut-off score for ADHD could be seen in the females. This also extended to the combined sample of males and females, $\chi^{2}(1, N=8,091)=11.1, p=0.001, \phi=0.04$, with odds ratio 1.27 (95\% CI $=1.10$ to 1.47$)$. Although the frequencies were consistently higher in the twins with a female co-twin also for the ASD cut-off scores, in both girls and boys, these differences did not reach statistical significance (Table 3).

\section{Discussion}

We have studied the effect of having a female or male co-twin on traits for autism and ADHD in a cohort of 9 and 12 year old Swedish dizygotic twins. Our study 
Table 2 Differences in autistic and ADHD traits between index twins with either a female or a male co-twin

\begin{tabular}{|c|c|c|c|c|c|c|c|c|}
\hline & \multirow[b]{2}{*}{ Index twin } & \multicolumn{2}{|c|}{ Female co-twin } & \multicolumn{2}{|c|}{ Male co-twin } & \multirow[b]{2}{*}{ Mann-Whitney U } & \multirow[b]{2}{*}{$P$} & \multirow[b]{2}{*}{$r$} \\
\hline & & $\bar{N}$ & Mean rank & $\bar{N}$ & Mean rank & & & \\
\hline \multirow[t]{2}{*}{ ADHD traits } & Female & 1793 & 3063 & 4195 & 2961 & $3,626,673$ & 0.03 & 0.03 \\
\hline & Male & 4190 & 3179 & 2109 & 3091 & $4,295,000$ & 0.06 & 0.02 \\
\hline \multirow[t]{2}{*}{ Autistic traits } & Female & 1795 & 3099 & 4197 & 2953 & $3,582,249$ & 0.001 & 0.04 \\
\hline & Male & 4197 & 3160 & 2115 & 3150 & $4,425,446$ & 0.8 & - \\
\hline
\end{tabular}

ADHD and autistic traits measured by the Autism-Tics, AD/HD, and other Comorbidities inventory (A-TAC). $r$ effect size

aimed to explore the hypothesis that elevated levels of prenatal testosterone increase the risk of developing autistic and/or ADHD-related traits, under the assumption that elevated testosterone levels from a dizygotic male twin fetus will increase testosterone exposure of its cotwin, leading to a masculinization of the brain. Contrary to what we had predicted, no increase in autistic traits could be found in girls with a male co-twin compared with those with a female co-twin. Instead, the opposite result was found, that girls with a female co-twin were reported to have more ADHD and autistic traits than girls with a male co-twin. It was also significantly more common for boys and girls with a female co-twin to reach the lower cut-off for ADHD than for those with a male co-twin. Although the same pattern was notable with respect to the cut-off for ASD, these differences were too small to reach statistical significance. In the analysis of the different A-TAC module scores, differences in scores between having a female co-twin and a male co-twin were present for the $\mathrm{AD} / \mathrm{HD}$ module attention/concentration, the ASD modules flexibility, and social interaction, and also for the perception module. Although the perception module, which includes items regarding sensory hyper reactivity, is a stand-alone module in the A-TAC, it should be noted that the DSM-5, in addition to the DSM-IV criteria, includes hyper-/hyporeactivity to sensory input in its ASD criteria. Thus, the difference found in the perception can also be interpreted as related to ASD. Notably, all module score differences for boys and girls alike pointed in the same direction, that is, towards higher scores in twins with a female co-twin.

Although the main analysis included two comparisons, no correction of $p$ values was undertaken. Whereas the association between sex of co-twin and ASD scores would remain significant also following such an adjustment, the association between sex of co-twin and ADHD scores would not. The latter relationship, not being a chance finding, however, gains support from the analysis regarding cut-off for ADHD diagnosis, as well as from the fact that our observation is in line with a previous report from Attermann and co-workers [36]; these authors, however, found no corresponding effect for males. Also, a greater aggregation of autistic symptoms in siblings of female probands with high scores as compared to siblings with male probands with high scores, interpreted as a protective effect exerted by the female sex, has previously been reported on a study partly based on the same cohort [6].

There are several possible explanations for the higher scores in female twins with a twin sister, and they may not be the same for the ASD and ADHD traits. One explanation could be parent rater contrast effects, that is, an existing difference between the twins amplified by the rater. As the rated traits of ASD and ADHD are generally more frequent in males, the risk of an underreporting of traits in the female twin due to a contrast effect will be larger in the opposite-sex twins than in the same-sex twins. Additionally, the contrast effect may result in underreporting also when the co-twin is afflicted by a neuropsychiatric disorder, and as both ASD and ADHD are more common in boys than girls, such an effect would have a bigger impact on the twins with a male co-twin. Such a bias playing a role gains support from the fact that we, unlike Attermann and co-workers [36], observed a corresponding effect of the sex of the co-twin on the attention/concentration and flexibility modules also in male twins. On the other hand, one should note that no such effect was seen for traits of

Table 3 Number of children, $n$ (\%), with scores for ADHD and autistic traits above validated cut-offs

\begin{tabular}{|c|c|c|c|c|c|c|c|c|}
\hline \multirow{3}{*}{$\begin{array}{l}\text { Cut-off } \\
\text { Index twin }\end{array}$} & \multicolumn{4}{|l|}{ ADHD } & \multicolumn{4}{|l|}{ ASD } \\
\hline & \multicolumn{2}{|l|}{$\geq 6$} & \multicolumn{2}{|l|}{$\geq 12.5$} & \multicolumn{2}{|l|}{$\geq 4.5$} & \multicolumn{2}{|l|}{$\geq 8.5$} \\
\hline & $\mathrm{F}^{* *}$ & $M$ & $\mathrm{~F}$ & $M$ & $\mathrm{~F}$ & $M$ & $\mathrm{~F}$ & $M$ \\
\hline Female co-twin & $137(7.6)$ & $595(14.2)$ & $17(0.9)$ & $125(3)$ & $40(2.2)$ & $220(5.2)$ & $10(0.6)$ & $58(1.4)$ \\
\hline Male co-twin & $247(5.9)$ & $274(13)$ & $39(0.9)$ & $52(2.5)$ & $81(1.9)$ & $103(4.9)$ & $23(0.5)$ & $25(1.2)$ \\
\hline
\end{tabular}

ADHD and autistic traits measured by the Autism-Tics, AD/HD, and other Comorbidities inventory (A-TAC)

$F$ female index twin, $M$ male index twin

${ }^{* *} p=0.01$ for $X^{2}$ analysis between female and male co-twins 
impulsiveness/activity, language, emotion, and opposition in either sex, similarly known to differ between genders. Moreover, previous studies of parent rating contrast effect in dizygotic twins have shown larger effects in straightforward traits as shyness and hyperactivity [43, 44], while a less observable trait such as attention has shown very little contrast effect in this age group [45]. In addition to the possible bias from twin comparison, underreporting may also arise from concealed traits. Thus, as girls are generally more socially responsive [46] and able to recognize need-of-help [47], there is a possibility that, in cases where both twins have many ADHD symptoms, the girl makes a greater effort to manage herself in order to take responsibility also for her co-twin. Thus, the severity of ADHD symptoms in a girl with a co-twin with even more traits might be underestimated.

Although this study does not provide support for the prenatal testosterone hypothesis for autism, it also does not refute it. First, both the reporting bias discussed above (see also [36]), and the tentative protective effect of the female gender [5-7], may serve to mask a riskenhancing effect of increased in utero testosterone exposure in females with a male twin. Second, the functional relevance effect of testosterone transfer between human twins is not fully established. Third, the risk associated with high prenatal testosterone levels may be associated with testosterone levels that are higher than those tentatively caused by amniotic testosterone transfer in humans. And fourth, one cannot exclude the existence of a complex association between prenatal testosterone and neuropsychiatric symptoms, where moderately elevated levels (caused by diffusion from a male co-twin) may lead to a reduced responsiveness to the hormone, hence reducing the influence of a sudden rise in testosterone level produced by the fetus or the mother.

There are some limitations to the present study. One is that neuropsychiatric traits were only assessed by parental assessment and by means of layman interviews. However, A-TAC is thoroughly validated and the cutoffs reliably mirror current estimates of the prevalence of ADHD and ASD, respectively [48], in the Swedish population. Another limitation is that the DSM-IV criteria for ASD, on which A-TAC is based, mainly reflect the symptomatology displayed by males and that the presentation of ASD may be different in girls [49], hence making the A-TAC assessment of autistic traits in girls less certain. The major strengths of this study are that it is based on a large sample of twins and the use of a well-established and fairly comprehensive rating scale.

\section{Conclusions}

There is a small but increased risk for dizygotic twins with a female co-twin of displaying a high degree of parent-reported ADHD traits when compared with those with a male co-twin, indicating a possible protective effect of having a twin brother. Having a female co-twin is also associated with slightly elevated autistic traits, especially in the domains concerning flexibility of thought and social interaction, thus adding an intriguing complication to the hypothesis that elevated prenatal testosterone levels causes an increased frequency of autistic traits.

\section{Abbreviations \\ ADHD: attention-deficit/hyperactivity disorder; ASD: autism spectrum disorder; A-TAC: Autism-Tics, ADHD, and other Comorbidities inventory; CATSS: Child and Adolescent Twin Study in Sweden.}

\section{Competing interests}

The authors declare that they have no competing interests.

\section{Authors' contributions}

SB and EE planned the study. PL and SL provided the data and knowledge from the CATSS study. JE made the analyses. JE wrote the article with contributions from all other authors (SL, SB, PL, and EE). All authors read and approved the final manuscript.

\section{Acknowledgements}

This project was supported by the Swedish Research Council (Grant No 523-2011-3646), The Brain Foundation, Bertil Hållsten's Foundation, and Söderström's foundation. The CATSS study was supported by the Swedish Council for Working Life, funds under the ALF agreement, the SöderströmKönigska Foundation, and the Swedish Research Council (Medicine and SIMSAM). The funders had no role in the study design, data collection and analysis, decision to publish, or preparation of the manuscript. Many thanks also to Eva Hesselmark for her valuable comments.

\section{Author details}

${ }^{1}$ Department of Clinical Neuroscience, Karolinska Institutet, KIND, Gävleg 22, SE-113 30, Stockholm, Sweden. ${ }^{2}$ Centre for Ethics, Law and Mental Health (CELAM), University of Gothenburg, Gothenburg, Sweden. ${ }^{3}$ Gillberg Neuropsychiatry Centre, University of Gothenburg, Gothenburg, Sweden. ${ }^{4}$ Department of Medical Epidemiology and Biostatistics, Karolinska Institutet, Stockholm, Sweden. ${ }^{5}$ School of Medical Sciences, Örebro University, Örebro, Sweden. ${ }^{6}$ Department of Pharmacology, Institute of Neuroscience and Physiology, Sahlgrenska Academy, University of Gothenburg, Gothenburg, Sweden.

Received: 31 August 2015 Accepted: 12 January 2016

Published online: 19 January 2016

\section{References}

1. Connolly JJ, Hakonarson H. Etiology of autism spectrum disorder: a genomics perspective. Curr Psychiatry Rep. 2014;16:501.

2. Akutagava-Martins G, Salatino-Oliveira A, Kieling CC, Rohde LA, Hutz MH. Genetics of attention-deficit/hyperactivity disorder: current findings and future directions. Expert Rev Neurother. 2013;13:435-45.

3. Leitner $Y$. The co-occurrence of autism and attention deficit hyperactivity disorder in children—what do we know? Front Hum Neurosci. 2014;8:268,

4. Bohm HV, Stewart MG, Healy AM. On the autistic spectrum disorder concordance rates of twins and non-twin siblings. Med Hypotheses. 2013: 81:789-91.

5. Jacquemont S, Coe BP, Hersch M, Duyzend MH, Krumm N, Bergmann S, et al. A higher mutational burden in females supports a "female protective model" in neurodevelopmental disorders. Am J Hum Genet. 2014;94:415-25.

6. Robinson EB, Lichtenstein P, Anckarsäter H, Happé F, Ronald A. Examining and interpreting the female protective effect against autistic behavior. Proc Natl Acad Sci U S A. 2013;110:5258-62.

7. Werling DM, Geschwind DH. Recurrence rates provide evidence for sexdifferential, familial genetic liability for autism spectrum disorders in multiplex families and twins. Mol Autism. 2015;6:27.

8. Asperger H. Die "Autistischen Psychopathen" im Kindesalter. Arch Psychiatr Nervenkr. 1944;117:76-136. 
9. Baron-Cohen S. The extreme male brain theory of autism. Trends Cogn Sci. 2002;6:248-54

10. Auyeung B, Baron-Cohen S, Ashwin E, Knickmeyer R, Taylor K, Hackett G. Fetal testosterone and autistic traits. Br J Psychol. 2009;100:1-22.

11. Auyeung B, Ahluwalia J, Thomson L, Taylor K, Hackett G, O'Donnell K, et al. Prenatal versus postnatal sex steroid hormone effects on autistic traits in children at 18 to 24 months of age. Mol Autism. 2012;3:17.

12. Baron-Cohen S, Auyeung B, Nørgaard-Pedersen B, Hougaard DM, Abdallah MW, Melgaard L, et al. Elevated fetal steroidogenic activity in autism. Mol Psychiatry. 2015;20:369-76.

13. Arnold AP. The organizational-activational hypothesis as the foundation for a unified theory of sexual differentiation of all mammalian tissues. Horm Behav. 2009;55:570-8.

14. Sarkar P, Bergman K, Fisk NM, O'Connor TG, Glover V. Amniotic fluid testosterone: relationship with cortisol and gestational age. Clin Endocrinol (Oxf). 2007;67:743-7.

15. Ryan BC, Vandenbergh JG. Intrauterine position effects. Neurosci Biobehav Rev. 2002;26:665-78.

16. Slutske WS, Bascom EN, Meier MH, Medland SE, Martin NG. Sensation seeking in females from opposite- versus same-sex twin pairs: hormone transfer or sibling imitation? Behav Genet. 2011;41:533-42.

17. Alexanderson C, Henningsson S, Lichtenstein P, Holmäng A, Eriksson E. Influence of having a male twin on body mass index and risk for dyslipidemia in middle-aged and old women. Int J Obes. 2011;35:1466-9.

18. Dempsey PJ, Townsend GC, Richards LC. Increased tooth crown size in females with twin brothers: evidence for hormonal diffusion between twins in utero. Am J Hum Biol. 1999;11:577-86.

19. Heikkinen T, Harila V, Tapanainen JS, Alvesalo L. Masculinization of the eruption pattern of permanent mandibular canines in opposite sex twin girls. Am J Phys Anthropol. 2013;151:566-72.

20. Voracek M, Dressler SG. Digit ratio (2D:4D) in twins: heritability estimates and evidence for a masculinized trait expression in women from oppositesex pairs. Psychol Rep. 2007;100:115-26.

21. Benetos A, Dalgård C, Labat C, Kark JD, Verhulst S, Christensen K, et al. Sex difference in leukocyte telomere length is ablated in opposite-sex co-twins. Int J Epidemiol. 2014:43:1799-805.

22. Cohen-Bendahan CCC, Buitelaar JK, Van Goozen SHM, Cohen-Kettenis PT. Prenatal exposure to testosterone and functional cerebral lateralization: a study in same-sex and opposite-sex twin girls. Psychoneuroendocrinology. 2004:29:911-6.

23. Cohen-Bendahan CCC, van de Beek C, Berenbaum SA. Prenatal sex hormone effects on child and adult sex-typed behavior: methods and findings. Neurosci Biobehav Rev. 2005;29:353-84.

24. Resnick SM, Gottesman II, McGue M. Sensation seeking in opposite-sex twins: an effect of prenatal hormones? Behav Genet. 1993;23:323-9.

25. Tapp AL, Maybery MT, Whitehouse AJO. Evaluating the twin testosterone transfer hypothesis: a review of the empirical evidence. Horm Behav. 2011; 60:713-22.

26. Henderson BA, Berenbaum SA. Sex-typed play in opposite-sex twins. Dev Psychobiol. 1997;31:115-23.

27. Loehlin JC, Martin NG. Dimensions of psychological masculinity-femininity in adult twins from opposite-sex and same-sex pairs. Behav Genet. 2000;30: 19-28.

28. Rose RJ, Kaprio J, Winter T, Dick DM, Viken RJ, Pulkkinen L, et al. Femininity and fertility in sisters with twin brothers: prenatal androgenization? Crosssex socialization? Psychol Sci. 2002;13:263-7.

29. Ahrenfeldt L, Petersen I, Johnson W, Christensen K, Registry DT, Denmark S. Academic performance of opposite-sex and same-sex twins in adolescence: a Danish national cohort study. Horm Behav. 2015;69:123-31.

30. Culbert KM, Breedlove SM, Burt SA, Klump KL. Comparison of opposite-sex and same-sex twins. Arch Gen Psychiatry. 2008;65:329-36.

31. Culbert KM, Breedlove SM, Sisk CL, Keel PK, Neale MC, Boker SM, et al. Age differences in prenatal testosterone's protective effects on disordered eating symptoms: developmental windows of expression? Behav Neurosci. 2015; 129:18-36.

32. Baker JH, Lichtenstein P, Kendler KS. Intrauterine testosterone exposure and risk for disordered eating. Br J Psychiatry. 2009;194:375-6.

33. Lydecker JA, Pisetsky EM, Mitchell KS, Thornton LM, Kendler KS, ReichbornKjennerud T, et al. Association between co-twin sex and eating disorders in opposite sex twin pairs: evaluations in North American, Norwegian, and Swedish samples. J Psychosom Res. 2012;72:73-7.
34. Raevuori A, Kaprio J, Hoek HW, Sihvola E, Rissanen A, Keski-Rahkonen A. Anorexia and bulimia nervosa in same-sex and opposite-sex twins: lack of association with twin type in a nationwide study of Finnish twins. Am J Psychiatry. 2008;165:1604-10.

35. Roberts BA, Martel MM. Prenatal testosterone and preschool disruptive behavior disorders. Pers Individ Dif. 2013;55:962-6.

36. Attermann J, Obel C, Bilenberg N, Nordenbæk CM, Skytthe A, Olsen J. Traits of ADHD and autism in girls with a twin brother: a Mendelian randomization study. Eur Child Adolesc Psychiatry. 2012;21:503-9.

37. Anckarsäter H, Lundström S, Kollberg L, Kerekes N, Palm C, Carlström E, et al. The Child and Adolescent Twin Study in Sweden (CATSS). Twin Res Hum Genet. 2011;14:495-508.

38. Hannelius U, Gherman L, Mäkelä V-V, Lindstedt A, Zucchelli M, Lagerberg C, et al. Large-scale zygosity testing using single nucleotide polymorphisms. Twin Res Hum Genet. 2007:10:604-25.

39. Hansson SL, Röjvall AS, Rastam M, Gillberg C, Gillberg C, Anckarsäter H. Psychiatric telephone interview with parents for screening of childhood Autism - Tics, Attention-deficit Hyperactivity Disorder and Other Comorbidities (A-TAC): preliminary reliability and validity. Br J Psychiatry. 2005;187:262-7.

40. Larson T, Anckarsäter H, Gillberg C, Ståhlberg O, Carlström E, Kadesjö B, et al. The Autism-Tics, AD/HD and other Comorbidities inventory (A-TAC): further validation of a telephone interview for epidemiological research. BMC Psychiatry. 2010;10:1.

41. Larson T, Lundström $\mathrm{S}$, Nilsson $T$, Selinus EN, Råstam M, Lichtenstein $\mathrm{P}$, et al. Predictive properties of the A-TAC inventory when screening for childhoodonset neurodevelopmental problems in a population-based sample. BMC Psychiatry. 2013;13:233.

42. Quade D. Rank analysis of covariance. J Am Stat Assoc. 1967;62:1187-200.

43. Saudino KI, Ronald A, Plomin R. The etiology of behavior problems in 7-year-old twins: substantial genetic influence and negligible shared environmental influence for parent ratings and ratings by same and different teachers. J Abnorm Child Psychol. 2005;33:113-30.

44. Saudino K, Wertz AE, Gagne JR, Chawla S, Carver CS. Night and day: are siblings as different in temperament as parents say they are. J Pers Soc Psychol. 2004;87:698-706.

45. Rietveld MJH, Hudziak JJ, Bartels M, van Beijsterveldt CEM, Boomsma Dl. Heritability of attention problems in children: longitudinal results from a study of twins, age 3-12 years. J Child Psychol Psychiatry. 2004:45:577-88.

46. Proverbio AM, Zani A, Adorni R. Neural markers of a greater female responsiveness to social stimuli. BMC Neurosci. 2008;9:56.

47. Stolarova M, Brielmann AA. Does anyone need help? Age and gender effects on children's ability to recognize need-of-help. Front Psychol. 2014;5:170.

48. Hansson Halleröd SL, Larson T, Ståhlberg O, Carlström E, Gillberg C, Anckarsäter H. The Autism-Tics, AD/HD and other Comorbidities (A-TAC) telephone interview: convergence with the Child Behavior Checklist (CBCL). Nord J Psychiatry. 2010;64:218-24.

49. Dworzynski K, Ronald A, Bolton P, Happé F. How different are girls and boys above and below the diagnostic threshold for autism spectrum disorders? J Am Acad Child Adolesc Psychiatry. 2012;51:788-97.

\section{Submit your next manuscript to BioMed Central and we will help you at every step:}

- We accept pre-submission inquiries

- Our selector tool helps you to find the most relevant journal

- We provide round the clock customer support

- Convenient online submission

- Thorough peer review

- Inclusion in PubMed and all major indexing services

- Maximum visibility for your research

Submit your manuscript at www.biomedcentral.com/submit 